\title{
MEASURING SUSPENDED SEDIMENT AND ITS WAVE AND TURBULENCE FORCING IN THE DEE ESTUARY
}

\author{
Rodolfo Bolanos ${ }^{1}$, Benjamin D. Moate ${ }^{1}$ and Alejandro Souza ${ }^{1}$
}

\begin{abstract}
Coastal areas support many human activities and represent a very important habitat for many marine and bird species. The Dee estuary, located in the eastern Irish Sea, is $20 \mathrm{~km}$ long, $8 \mathrm{~km}$ wide at the mouth and is characterized by a $10 \mathrm{~m}$ tidal range. Suspended and seabed sediments in the Dee contain a diverse assemblage of non-cohesive and cohesive sediments, and therefore the threshold of motion at the bed could be a complex process, dependent on several factors. In this paper, we present data collected during 2 deployments in the Dee, including both acoustic and optical instruments to study the link between the hydrodynamics, turbulence, and suspended sediments. Suspended sediment concentration is clearly controlled by tides following the flood/ ebb and spring/neap cycle. Moderate wave events were observed to increase sediment concentration, though mainly near the bed. High concentrations of silt and very fine sand were found that could support the flocculation processes during the flood and ebb cycle. Sediment concentrations at heights above $1 \mathrm{~m}$ from the bed do not present direct relation with bottom stress.
\end{abstract}

Key words: Dee estuary, hydrodynamics, suspended sediment, morphodynamics, turbulence.

\section{Introduction}

Coastal areas support many human activities and represent a very important habitat for many marine and bird species. In order to properly manage such areas, knowledge of the physical, biological and chemical processes is necessary and therefore the observation, quantification and simulation of such processes are a pre-requisite. Coastal waves and currents are highly variable and can have a significant impact on coastal erosion and sediment transport in coastal areas. This sediment transport (erosion, suspension and deposition) is largely controlled by the bed shear stress produced by the hydrodynamic conditions. Depending on the environment the hydrodynamics can be current-dominated, wave-dominated or a combination of both (Soulsby, 1997).

In this paper, analysis of field data is performed in order to asses the hydrodynamics and its links to sediment in suspension. First, the study area is presented. In section 2 the data and methods used are described. Results are shown in section 3 and finally some discussion and conclusions are drawn.

\subsection{Study area}

The Dee estuary (Fig. 1), located in the eastern Irish Sea, is $20 \mathrm{~km}$ long, $8 \mathrm{~km}$ wide at the mouth and is characterized by a $10 \mathrm{~m}$ tidal range. The Dee has undergone substantial levels of sedimentation over the past two centuries, resulting in land reclamation and salt marsh colonization. Moore et al (2008) showed the tidal asymmetry of the Dee and its relation to the overall sedimentation of the estuary. The Dee estuary presents a mixture of sediments containing a range of non-cohesive and cohesive sediments and, therefore, the threshold of motion of the bed might be a complex process dependent on several conditions. In recent years, the estuary has been the subject of an annual ship borne and mooring survey program, with a comprehensive suite of instruments deployed to measure and interpret the hydrodynamics, turbulence and sediment transport in the area. In the present paper we present a summary of the most recent data, collected February to March 2008, which encompassed the spring-neap tidal cycle and included several short storms.

${ }^{1}$ Proudman Oceanographic Laboratory, Joseph Proudman Building, 6 Brownlow Street Liverpool L3 5DA, UK. rbol@pol.ac.uk 


\section{Data and Methods}

The data presented were collected during 2 STABLE (Sediment Transport and Boundary Layer Equipment) benthic tripod platform deployments, in the Hilbre and Welsh channels at the mouth of the Dee (Fig. 1). A large tripod, STABLE-3.0, was deployed in the Hilbre channel, whilst a smaller version, mini-STABLE, was deployed in the Welsh channel. Both included a suite of optical and acoustic instruments and Table 1 summarizes the instrumentation present on each rig. The data cover a wide range of environmental conditions, being ideal to build an overall picture of the physical processes controlling the estuary. The aim of the deployments was to determine the link between the hydrodynamics, turbulence, bedforms and suspended sediments, and therefore the attention here is placed on data from the Acoustic Doppler Velocimeters (ADV), Acoustic Backscatter System (ABS), Laser In-Situ Scattering and Transmissometry (LISST), and Optical Backscatter Sensor (OBS).

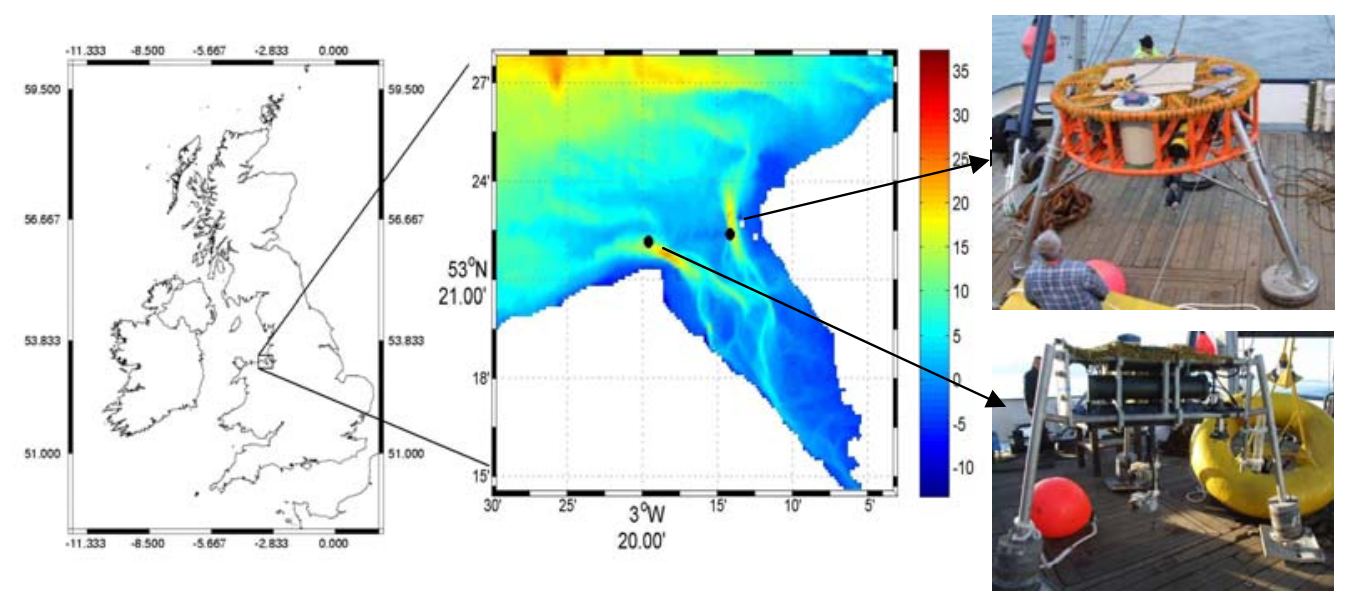

Figure 1. Location of study area, bathymetry of the Dee estuary and rigs deployed in the mouth of the Dee. The top right is the STABLE-3.0 located in the Hilbre channel, and bottom right the mini-STABLE deployed in the Welsh channel.

Table 1. Summary of rigs instrumentation.

\begin{tabular}{|c|c|c|}
\hline & STABLE-30 & Mini-STABLE \\
\hline \multirow{3}{*}{ Position } & Hilbre Channel & Welsh Channel \\
& $53^{\circ} 22.382^{\prime} \mathrm{N}$ & $53^{\circ} 22.156^{\prime} \mathrm{N}$ \\
& $3^{\circ} 14.147^{\prime} \mathrm{W}$ & $3^{\circ} 19.577^{\prime} \mathrm{W}$ \\
\hline \multirow{2}{*}{ Period of deployment } & $14 / 02 / 2008-$ & $12 / 02 / 2008-$ \\
& $11 / 03 / 2008$ & $13 / 03 / 2008$ \\
\hline \multirow{5}{*}{ Instrumentation } & 3 ADVs & 2 ADVs \\
& OBS & ABS \\
& ABS & 2-D ripple scanner \\
& LISST & LISST \\
& 3-D ripple profiler & ADCP \\
& ADCP 600 $\mathrm{MHz}$ & Pressure sensor \\
& ADCP $1200 \mathrm{MHz}$ & \\
\hline
\end{tabular}




\subsection{ADV data}

The ADVs provided collocated measurements of the 3 components of flow at high temporal resolution at a single point. Detailed quality control including despiking of ADVs data was carried out. The removal of spikes is necessary as they are known to erroneously modify the spectral analysis and estimation of bottom stress. The approach taken was following Goring and Nikora (2002) and modified by Wahl (2003). The method is based on a 3D Poincaré map in which each component of velocity and its first and second derivative are plotted against each other. The points located outside of the ellipsoid in the Poincaré map are excluded or replaced by a polynomial interpolation. This method has been used by Mori et al (2007) to clean ADV data in bubbly flows.

The despiking method was applied to all the raw ADV data. ADVs were operated in burst mode, on the hour for a duration of 20 minutes, with sampling frequencies of 8 and $16 \mathrm{~Hz}$ for the ADVs on STABLE-3.0 and mini-STABLE respectively. The ADVs were deployed on STABLE-3.0 at height of $0.4 \mathrm{~m}, 0.7 \mathrm{~m}$ and 1 $\mathrm{m}$ and on mini-STABLE at height of $0.35 \mathrm{~m}$ and $0.63 \mathrm{~m}$ above the bed.

The despiking method removed the anomalous peaks in the time series and conserved the underlying original properties. The spikes can appear in a record due to contamination of pulses, bubbles or large particular matter in the water column. Figure 2 shows an example of a time series before and after application of the despiking method.

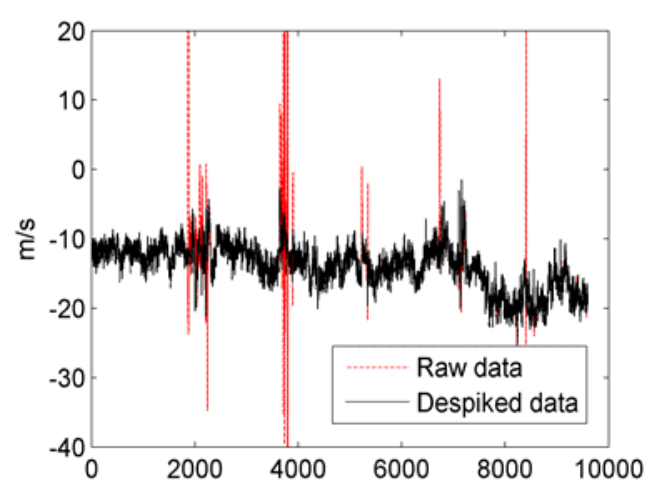

Figure 2. Example of a raw and despiked time series from ADV

\subsection{Wave data}

For the estimation of wave parameters, the PUV (pressure and velocity) method was applied to the ADV and pressure data. This method uses linear wave theory to convert velocity and pressure spectra to surface elevation spectra (Gordon and Lohrmann, 2001):

$$
\begin{aligned}
C_{\eta p} & =\left[\frac{\cosh (k h)}{\cosh k(h+z)}\right]^{2} \frac{C_{p}}{\rho^{2} g^{2}} \\
C_{\eta u} & =\left[\frac{\sinh (k h)}{\cosh k(h+z)}\right]^{2} \frac{C_{u}}{\sigma^{2}}
\end{aligned}
$$

where $\quad C_{\eta p} C_{\eta u}$ are surface elevation spectra based on pressure and velocity, $\mathrm{k}$ is wave number, $\mathrm{h}$ is the mean water depth relative to the seabed, and $\mathrm{z}$ is the vertical distance relative to the mean water level. In 
order to take into account the background currents the surface wave dispersion relation has been modified:

$$
\begin{aligned}
& \omega=\sqrt{g k \tanh k H}+k U \cos \alpha \\
& \omega \text { is frequency } \\
& k \text { is the wave number } \\
& U \text { is the background velocity } \\
& \alpha \text { angle between currents and waves }
\end{aligned}
$$

The wave direction was estimated by comparing the magnitude of the cross spectra at each frequency:

$$
\begin{aligned}
& D=\tan ^{-1}\left(C_{p u}(f) / C_{p v}(f)\right) \\
& C_{p u} \text { Cross spectra of pressure and u component } \\
& C_{p v} \text { Cross spectra of pressure and v component }
\end{aligned}
$$

The PUV method was used as it requires only a single point measurement of velocity and pressure. However, it requires a weighted average of the background current over the full water column to transfer the measurements to the surface, and here, only the velocity form the ADV was used. Another limitation is that at any given frequency the PUV will estimate a single direction.

ADCP wave data was used at STABLE-3.0 as there was no pressure sensor data available for the PUV. A comparison of the two ADCP wave data showed a very close agreement.

\subsection{Sediment in suspension}

Suspended load can significantly contribute to the total sediment transport, and when it occurs has been observed to exceed the bedload transport (Soulsby, 1997). In an environment such as the Dee, subject to large tidal currents, episodic wave events, and mixed sediments, sediment in suspension is an important variable that can determine the total transport of particles. In the present study, variables relating to sediment in suspension were measured with ABS, LISST and OBS. The LISST and OBS data were treated with the instrument calibration information. ABS data was inverted to obtain sediment concentration profiles. A description of these instruments and the data interpretation is presented below.

\subsubsection{ABS}

Acoustic backscatter techniques to measure suspended sediments have gained in popularity over the last 2 decades (Young et al., 1982, Vincent et al, 1991; Crawford and Hay, 1993; Thorne and Hardcastle, 1997). In the present study, multi-frequency ABS instruments operating at 1, 2 and $4 \mathrm{MHz}$ were deployed on both STABLE rigs, though the ABS on mini-STABLE failed to record. The instruments were designed in-house and measure the envelope of the backscattered signal at intervals of $0.01 \mathrm{~m}$ over a range of $1.28 \mathrm{~m}$. A pulse repetition frequency of $128 \mathrm{~Hz}$ was used with a system generated ensemble average produced every 32 pings, generating one recorded profile every 0.25 seconds. The instruments were calibrated following the procedure described by Betteridge et al (2008). Using the intrinsic scattering properties of irregularly shaped quartz sediments available in the literature (Thorne and Meral, 2008), iterative, semi-analytical inversions of the ABS data were conducted utilizing the LISST data to account for the size distribution, which is known to significantly alter the ensemble scattering properties of marine suspensions (Thorne and Meral, 2008; Thorne et al, 2007).

\subsubsection{LISST}

LISST instruments provide estimates of particle size, operating on the principle of laser diffraction. There are 2 standard LISST models, each designed to measure different size ranges. In the present study type-C LISSTs were deployed, measuring particles in the 2.5 to $500 \mu \mathrm{m}$ diameter range across 32 log spaced bins. Application of the manufacturers calibrations results in a volume distribution in units of microliters per liter, which is the measurement unit that will be utilized here. The LISST does not require routine calibration, though the laser optics must be checked on a regular basis to ensure that they remain properly aligned 
(Styles, 2006). Apart from the use of the calibration and background scatter of the instrument, the data did not require further cleaning. The LISST were deployed on STABLE-3.0 lat a height of $1.8 \mathrm{~m}$ and on miniSTABLE at a height of $1.56 \mathrm{~m}$.

\subsubsection{OBS}

Turbidity sensors measure the amount of light transmission of water to give a measurement of the suspended solids in that water. They were deployed on STABLE and connected to the ADVs. Unfortunately only one OBS recorded successfully at the height of $1 \mathrm{~m}$.

\subsection{Bottom stress}

\subsubsection{Inertial Dissipation method}

The inertial dissipation method is used to estimate the friction velocity, where the friction velocity is defined as (Green, 1992):

$$
U_{*}=(k z)^{1 / 3}\left[E(k) \alpha_{i}^{-1} k_{1}^{5 / 3}\right]^{1 / 2}
$$

where $E(k)$ is the energy spectrum. The constant $\alpha$ takes the value of 0.51 for spectra in the direction of the mean flow and 0.69 for the spectra of a transverse component of the main flow. The spectrum is defined such that the sum over all positive frequencies yields the variance of the velocity component.

To estimate the wave number spectra from the frequency spectra the "frozen-turbulence hypothesis" has been applied yielding:

$$
k=2 \pi f / U \quad E(k)=E(f)(U / 2 \pi)
$$

Once having the wave number spectra it was necessary to identify the valid wave numbers for the inertial sub-range. Following Green (1992) the lower wave number was defined as the largest of $2 \pi / z$ and the lowest measured wave number. The highest wave number limit was defined as the smallest of the highest measured wave number, $2 \pi / L_{d}$, and $2 \pi / L_{s}$. Typically $L_{d}=0.1 \mathrm{~cm}$ in the sea (Soulsby, 1983). $2 \pi / L_{s}$ represents a kind of half-power point that reflects spatial averaging by the sensor, in this case (for the ADV) $L_{s}=0.01$ was used, being $\sim$ the sample volume of the instrumentation.

In order to provide a higher order of confidence with the method, evaluation of stresses were performed considering different parts of the tail of the spectra when fitting the linear tail. The wavenumber corresponding to $1 \mathrm{~Hz}$ was identified (above this wave effects are negligible) and a linear fit was applied to 3 parts of the spectra: i) full range defined by the inertial dissipation method, ii) from the wavenumber corresponding to $1 \mathrm{~Hz}$ to the upper limit estimated by the inertial dissipation method and iii) from the lowest limit from the inertial dissipation method to the value of $1 \mathrm{~Hz}$. This procedure was applied to both, vertical and horizontal velocity component. Figure 3 shows an example of spectra from the horizontal and vertical velocity component. Some wave effects are evident at the horizontal wave spectra. From the different tail fittings it was found that using the vertical component and the last part of the tail produced the slope closest to the theoretical one and therefore was the one used for the estimation of stress. 


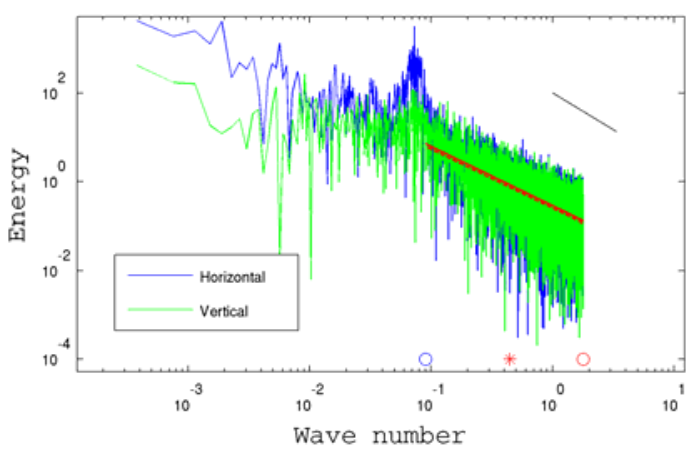

Figure 3. Spectra of horizontal and vertical components of the velocity. Lines in the tail of the spectra shows the linear fit, black line on the top left represents the $-5 / 3$ slope.

2.4.2 Reynolds stress method

Near the bed a constant stress layer is formed in which a logarithmic velocity profile is formed and the Reynolds stress equals the bottom stress (Howard and Souza, 2005). An estimate of the bottom stress is obtained from mean Reynolds stresses:

$$
\tau=\rho\left(\overline{u w}^{2}+\overline{v w}^{2}\right)^{1 / 2}
$$

It is assumed that the presence of waves has little effect as it is assumed that $u$ and $v$ are $180^{\circ}$ out of phase with $w$. However this neglects turbulence generated at the bed by combined waves and currents.

\section{Results}

\subsection{Hydrodynamics}

Figure 4 shows time series of hydrodynamic parameters at Hilbre channel during the deployment period. Current speed is controlled by tides and it follows the spring/neap and flood /ebb cycle. Velocities at this location are slightly larger during flood. Wave parameters are modulated by tide and the wave event during the second neap period, observed in the Welsh channel, is not present in the Hilbre channel due to a possible dissipation of energy when waves propagate in the estuary mouth. Current direction at the Hilbre channel location is aligned with N-S and E-W at the Welsh channel. The ebbs at the Welsh channel produce a change in current direction that could be attributed to eddy formation due to curvature of channel, interaction with the fame and with the coastline ledge. Wave direction is predominantly from $\mathrm{E}$ and NE at the Welsh channel, however at the Hilbre predominant directions are from north, in agreement with the channel orientation. 

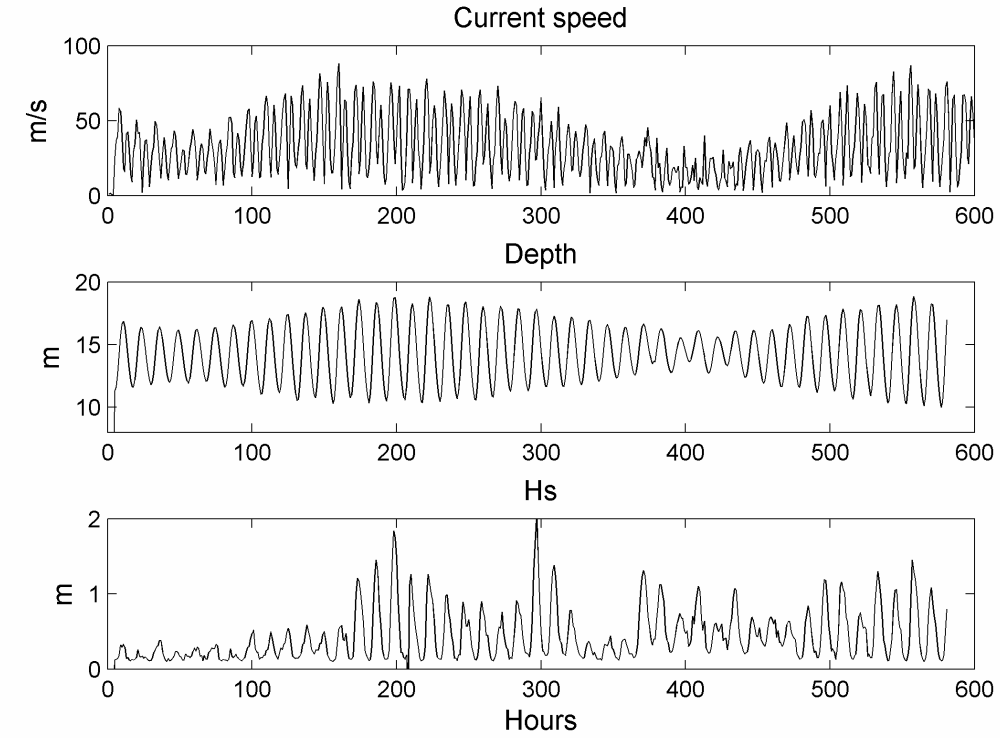

Figure 4. Time series at Hilbre channel. Current speed from ADV (top), water depth from ADCP (middle) and significant wave height from ADCP (bottom).

\subsection{Bottom stress}

At the Welsh channel the floods (about $1 \mathrm{~N} / \mathrm{m}^{2}$ ) produce less friction velocity for the same horizontal velocity than the ebbs. Bottom stress from Reynolds stress present similar behavior (and magnitude) as the inertial dissipation. The use of turbulence only time series significantly reduces the estimates.

Figure 5 shows a time series of bottom stress at the Hilbre channel during the transition from neap to spring tides. The bottom stress from the inertial dissipation presents similarities at flood and ebb with values of the order of $1 \mathrm{~N} / \mathrm{m}^{2}$. The use of the vertical velocity spectra produces a slight reduction of the estimates. The use of the Reynolds stresses produces an asymmetry between flood and ebb with the ebb stresses being larger.

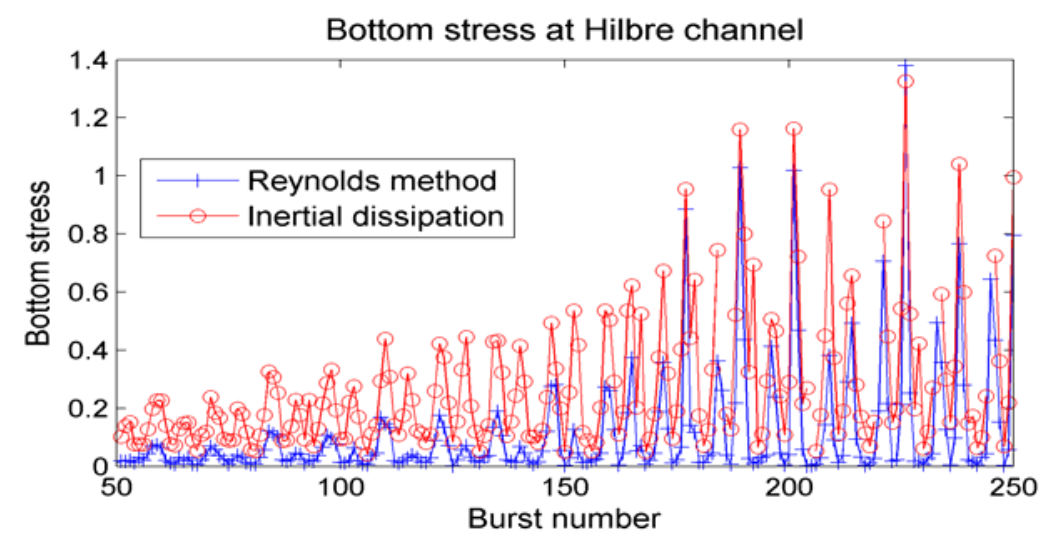

Figure 5. Time series of bottom stress at Hilbre channel during the transition from neap to spring tides with both methods. 


\subsection{Sediment in suspension}

Here, the LISST is used to provide an indication of the sediment size distribution in the area. Figure 6 shows a distribution of sediment during the first days of deployment at STABLE-3.0 and mini-STABLE and in a time when the smallest particles dominates (to reduce possible shifting of the distribution due to flocculation). Its shows a dominance of small particles with a diameter around 70 microns which represent the limit between silt and very fine sand, there is also an important contribution of fine sand. Both locations show the same pattern in size distribution, but larger concentrations at the Welsh channel. The large concentration of cohesive particles could support the formation of flocs at some stage of the tidal cycle.

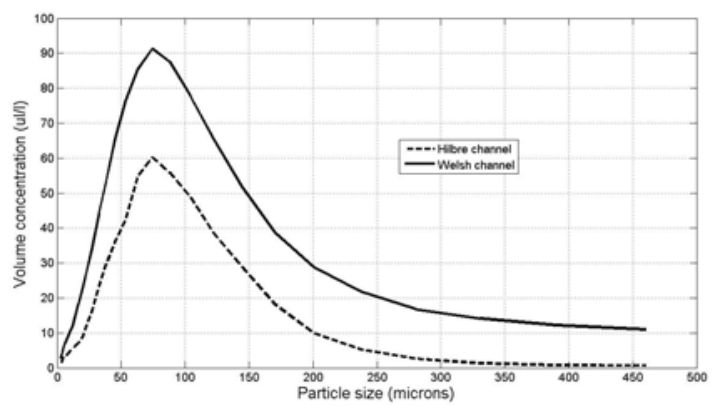

Figure 6. Size distribution of suspended sediment during the first day of deployment.

Figure 7 shows time series of integrated parameters from the LISST and the OBS at STABLE-3.0 in the Hilbre channel. The behaviors of the mean concentration and the cumulative concentration is very similar. The suspended sediment concentration from the LISST is not clearly related to flood and ebb but there is an evident signal that correlates with the spring-neap cycle. The standard deviation of the size is linearly related to the concentration, the larger the concentration the larger the size distribution. The peak size of the distribution shows an interesting pattern, the time series shows that, in contrary to concentration, large particles are present for both spring and neap tides and this might be controlled by flood and ebb cycle. The turbidity data from the OBS shows a very similar pattern as the concentration from the LISST showing a large correlation, a strong neap/spring signal. The mild wave events have a slight effect on sediment concentration from the LISST. It can be observed a rise of concentration and turbidity in the burst 380 that agrees with a wave event. Interestingly the turbidity from the OBS is not significantly modified.

Figure 8 shows scatter plots of north component of velocity (component along the channel) and bottom stresses and concentration. It is clear the direct relationship between velocity and bottom stress outlining the effect of the tidal cycle. However the concentration from the LISST presents large scatter when compared with bottom stress. This shows that the concentration at $1.5 \mathrm{~m}$ above the bed is not a pure representation of bottom processes but it could also involve some flocculation and small particle processes that might need longer time to react to environmental conditions. 

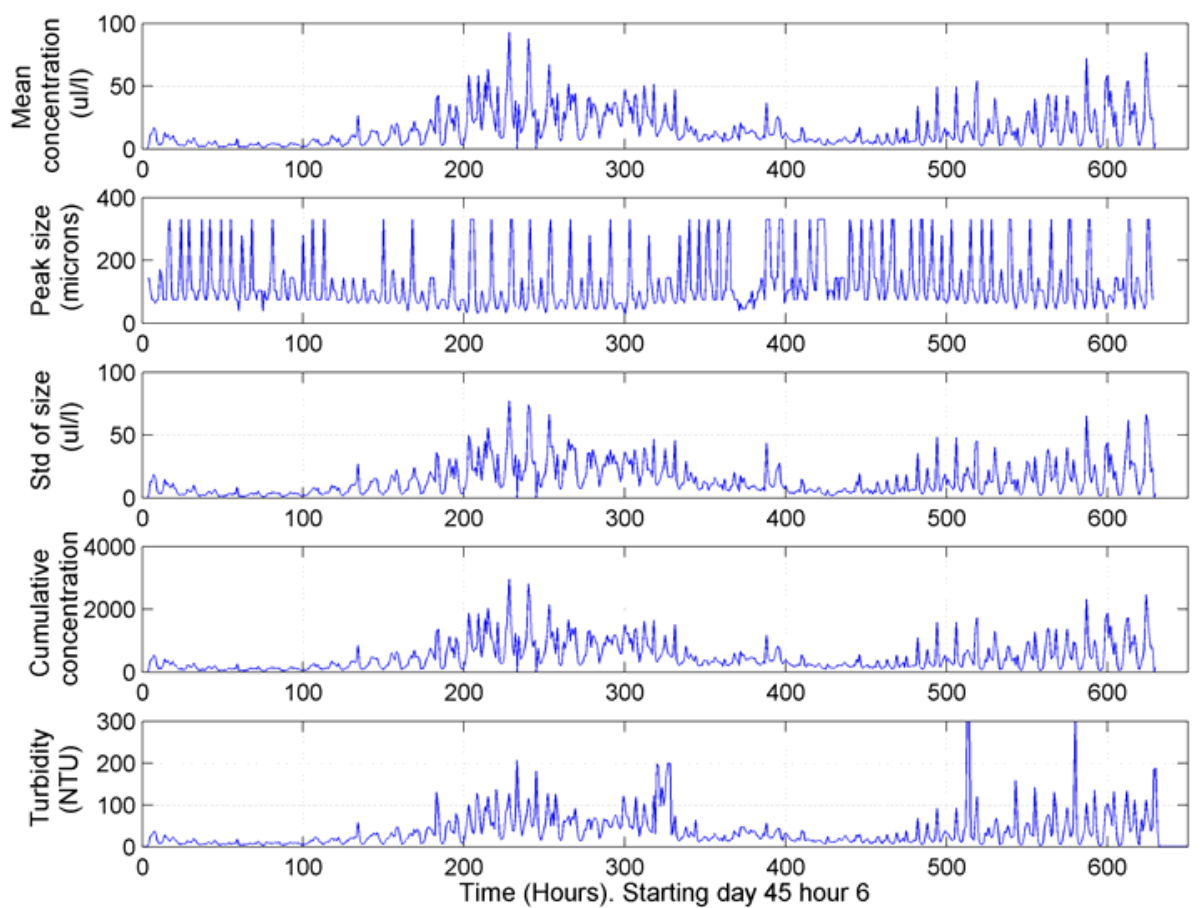

Figure 7. Time series of integrated parameters from the LISST. Top panel is the mean concentration. Second panel is the peak size, third panel is the standard deviation of the size, the fourth panel is the cumulative concentration. Last panel is turbidity from the OBS sensor.
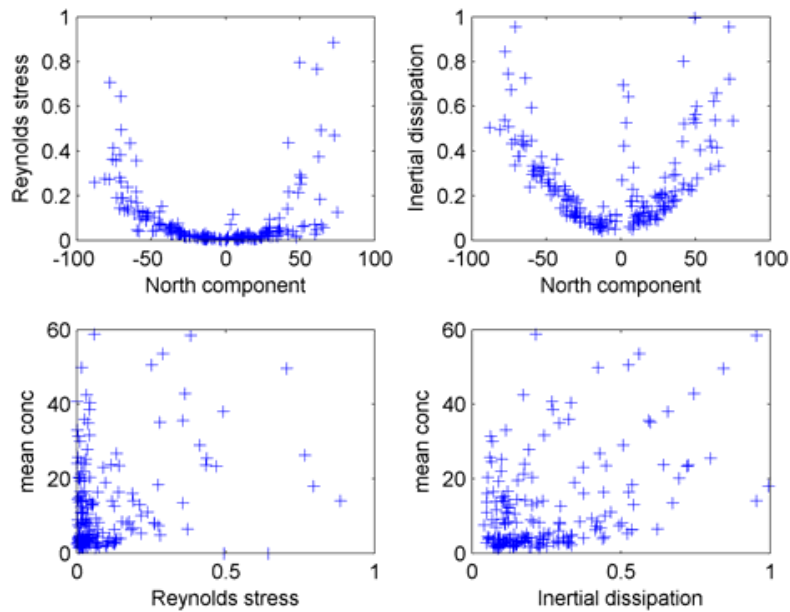

Figure 8. Scatter plot of bottom stress and north velocity component and suspended sediment concentration. 
Preliminary suspended sediment profiles from ABS (g/l) are presented in figure 9 together with significant wave height and water depth during the end of the neap tides and including a wave event. The figure shows that very near the bed (less than $1 \mathrm{~m}$ ) sediment in suspension is increased by flood and ebb currents and in a larger fashion by the wave event. The figure also shows that the sediment concentration near the bed is very sensitive to the change of spring and neap tides. Larger concentrations during the floods are also apparent in the figure.

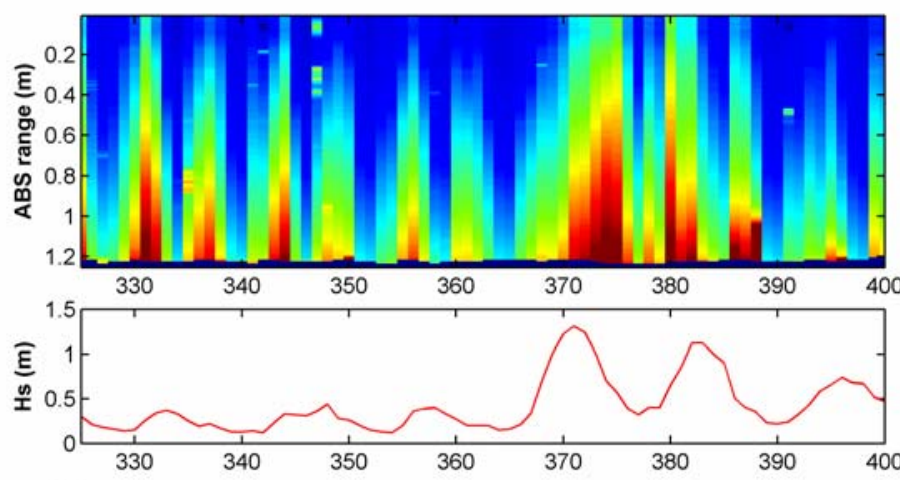

(a)

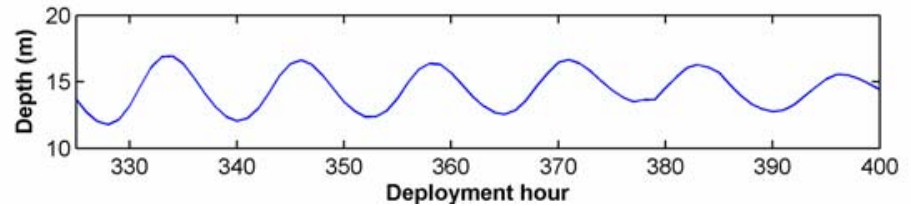

(c)

Figure 9. Suspended sediment and hydrodynamic conditions during the start of neap tides and a storm wave event. Sediment concentration profile from ABS (a) Significant wave height, (b) and water depth (c)

\section{Discussions and conclusions}

Previous studies have shown that the Dee presents a mix of cohesive and non cohesive sediments. This important property can control the formation of ripples and the behavior of the re-suspension of sediment. In this paper, we have shown that the Hilbre and Welsh channels present different bottom stress and turbulence behavior. One of the main differences between the 2 locations is the asymmetry of bottom stress found during flood and ebb at the Welsh channel. These differences might be produced by a complex eddy formation during the ebb tide due to the curvature of the channel and interaction with bathymetry. This is also observed by changes in horizontal velocity direction during ebbs, a process that also affects significantly the behavior of the vertical velocity. A second difference is that the Welsh channel location was more exposed to the wave events during neap tides and therefore some bottom stress due to wave and current interaction could be expected.

The fact that the LISST data does not correlate well with bottom stress is not surprising as the LISST was located at about $1.5 \mathrm{~m}$ above the bed and therefore the LISST data might explain only aggregation and braking of particles and not the instantaneous local resuspension of sediment from the bed. ABS data present a slight diferent patter than the LISST recording an important increase of sediment concentration near the bed during the wave event. 
Suspended sediment concentration is clearly controlled by tides following the flood/ ebb and spring/neap cycle. Moderate wave event can increase sediment concentration mainly near the bed. It was found a high concentration of silt and very fine sand that could support the flocculation processes following the flood and ebb cycle.

\section{Acknowledgements}

Authors thank the support of the FORMOST (Field observation and modelling of the sediment triad) NERC project.

\section{References}

Wahl, T. L. 2003. Discussion of "Despiking acoustic doppler velocimeter data” by Derek G. Goring and Vladimir I. Nikora. Journal of Hydraulic Engineering, 129(6) 484-487.

Green, M. 1992. Spectral estimate of bed shear stress at subcritical Reynolds numbers in a tidal boundary layer, Journal of Physical Oceanography, 22, 903-917.

Souza, A. J. and Howarth, M.J., 2005. Estimates of Reynolds stress in a highly energetic shelf sea. Ocean Dynamics, 55, 490-498.

Souza, A.J., L.G. Alvarez and Tommy Dickey. 2004. Tidally induced turbulence and suspended sediment. Geophys. Res. Lett.31, L20309, doi:10.1029/2004GL021186.

Betteridge, K.F.E., Thorne, P.D. and Cooke, R.D., 2008. Calibrating multi-frequency acoustic backscatter systems for studying near-bed suspended sediment transport processes. Continental Shelf Research, 28, 227-235.

Crawford, A.M. and Hay, A.E., 1993. Determining suspended sand size and concentration from multifrequency acoustic backscatter. J. Acoust. Soc. Am., 94 (6), 3312-3324.

Gordon, L., and Lohrman, A., 2001. Near-shore Doppler current meter wave spectra. Ocean wave measurement and analysis, ASCE Waves 2001 Conference. 33-43 pp.

Goring D.G., Nikora V.I. (2002) Despiking Acoustic Doppler Velocimeter Data. Journal of Hydraulic Engineering 128(1): 117.

Green, M., 1992. Spectral estimates of bed shear stress at subcritical Reynolds numbers in a tidal boundary layer. Journal of Physical Oceanography, Vol. 22 903-917.

Hay, A.E.; Sheng, J. Vertical profiles of suspended sand concentration and size from multifrequency acoustic backscatter. Journal of Geophysical Research 1992, 97(10), 15661-15677.

Howarth, M.J. and Souza, A.J., 2005. Reynolds stress observations in continental shelf seas. Deep-sea research $\mathrm{II}, 52,1075-1086$.

Moore, R.D., Wolf, J., Souza, A.J., Flint, S.S. 2009. Morphological evolution of the Dee estuary, eastern irish sea, UK: a tidal asymmetry approach. Geomorphology, 103, 588-596.

Mori, N., T. Suzuki and S. Kakuno (2007) Noise of Acoustic Doppler Velocimeter data in bubbly flow, Journal of Engineering Mechanics, 133, Issue 1, pp. 122-125.

Soulsby, R.L. 1983. The bottom boundary layer of shelf seas. Physical Oceanography of Coastal and Shelf Seas, B. Johns Ed., Elsevier, 189-266

Soulsby, R.L. 1997. Dynamics of marine sands. Thomas Telford Services Ltd. 249 pp.

Soulsby, R. L., and J. D. Humphery, Field observations of wave-current interaction at the sea bed, in Water Wave Kinematics, edited by A. Torum and O. T. Gunmestad, pp. 413 - 428, Kluwer Acad., Norwell, Mass., 1990.

Styles, R. Laboratory evaluation of the LISST in a stratified fluid. Marine Geology 2006, 227, 151- 162

Thorne, P.D.; Campbell, S.C. 1992. Backscattering by a suspension of spheres. Journal of the Acoustical Society of America, 92, 978-986.

Thorne, P.D.; Hardcastle, P.J. Acoustic measurements of suspended sediments in turbulent currents and comparison with in-situ samples. Journal of the Acoustical Society of America 1997, 101 (5)(Pt. 1), 2603-2614.

Thorne, P.D; Hanes, D.H. A review of acoustic measurement of small-scale sediment processes. Continental Shelf Research 2002, 22, 603-632. 
Thorne, P.D. and Meral, R., 2008. Formulations for the scattering properties of suspended sandy sediments for use in the application of acoustics to sediment transport processes. Continental Shelf Research, 28, 309-317.

Young, R.A., Merrill, J.T., Clarke, T.L. and Proni, J.R., 1982. Acoustic profiling of suspended sediments in the marine bottom boundary layer. Geophysical Research Letters, 9 (3), 175-178.

Vincent,C.E., Hanes, D.M. and Bowen, A.J., 1991. Acoustic measurements of suspended sand on the shoreface and the control of concentration by bed roughness. Marine Geology, 96, 1-18.

Wahl, T. L., 2003, Discussion of "Despiking Acoustic Doppler Velocimeter Data". Journal of Hydraulic Engineering, Vol. 129, No. 6

Williams, J.J., Bell, P.S., Coates, L.E., Metje, N. and Selwyn, R. 2003. Interactions between a benthic tripod and waves and a sandy bed. Continental Shelf Research, 23, 355-375. 